\title{
THE ASSOCIATION BETWEEN EMOTIONS AND PUBLIC ACCEPTANCE OF RECYCLED WATER FOR URBAN RESIDENTS
}

\author{
Yizhe DING, Xiaojun LIU* \\ School of Management, Xian University of Architecture and Technology, 710055 Xian, China
}

Received 30 March 2020; accepted 5 October 2020

\begin{abstract}
Worldwide water scarcity has prompted governments to develop alternative water resources, and public acceptance plays a critical role in the implementation of recycled water projects. The aim of this study was to explore how public acceptance can be affected by people's emotional responses to recycled water. In study 1, the general population was divided into four groups, clustering analysis with the intensity of various emotions was conducted, and the association between emotions and acceptance was explored. In study 2, the emotions, people's acceptance, and "objects of care" of water treatment experts were compared with those of members of the general population for further study. We found that the objects of care shortened the psychological distance between individuals and recycled water, which led people to generate specific emotions to recycled water. In a broader context, the study suggested that various emotions motivate people's behavior to accept or oppose the use of recycled water.
\end{abstract}

Keywords: recycled water, public acceptance, emotion, care, psychological distance.

\section{Introduction}

Ensuring an adequate residential water supply remains a challenge in many countries around the world. It has been predicted that about half of the population globally lives in an area with a water shortage, and the world will face a $40 \%$ shortfall in the water supply by 2030 (UNESCO, 2015). To solve the global problem of water scarcity, developing alternative water resources is crucial. Although recycled water is beneficial to supplying sufficient water and conserving conventional water resources, and potable recycled water was successfully used in many countries (Lee \& Tan, 2016), many people oppose recycled water. For instance, a number of recycled water projects failed in Australia because of local opposition (Hurlimann \& Dolnicar, 2010; Hurlimann \& McKay, 2004). In the northwestern area of China, where the climate is dry and rainless, a low level of waste water was reused because of people's opposition (Gu et al., 2015). In fact, in China, public programs have always paid attention to the technology (Chen et al., 2017), price, and quality criteria of recycled water, but they have only recently begun to focus on public acceptance of recycled water (Chen et al., 2015; Hou et al., 2021) and the related emotions and psychology (Fu \& Liu, 2017a). It has been suggested that public acceptance plays a vital role in initiating and implementing recycled wa- ter projects. A growing body of research focuses on the reasons for individuals' acceptance or resistance to recycled water and how to promote public acceptance. For example, previous study has shown that risk perception, emotion of disgust, and affect influence the acceptance of water reuse significantly (Fu et al., 2020; Garcia-Cuerva et al., 2016). The previous work has suggested that public acceptance falls as human contact with recycled water increases (Adapa, 2018; Browning et al., 2011; Dolnicar \& Schafer, 2009; Lease et al., 2014). Recent research showed that the more recycled water is used for personal purposes, the lower the public acceptance (Hurlimann \& Dolnicar, 2016). In contrast, recycled water for public or home irrigation was accepted by more than $80 \%$ of participants in some studies (Savchenko et al., 2018). Moreover, there have been several studies highlighting the impact of psychological indicators on the acceptance of recycled water. From a psychological viewpoint, it has been found that individuals' resistance or acceptance to recycled water can be associated with the emotion of disgust and contamination sensitivity (Rozin et al., 2015). Previous research has also shown that the stronger people feel disgust, the lower the public acceptance of recycled water (Wester et al., 2016). Other studies suggested that positive emo-

*Corresponding author. E-mail: xjun_liu@163.com

Copyright $\odot 2021$ The Author(s). Published by Vilnius Gediminas Technical University

This is an Open Access article distributed under the terms of the Creative Commons Attribution License (http://creativecommons.org/licenses/by/4.0/), which permits unrestricted use, distribution, and reproduction in any medium, provided the original author and source are credited. 
tions are expected to promote public acceptance because positive emotions can reduce people's risk perceptions (Smith \& Leiserowitz, 2014). Risk perception has a negative correlation with individuals' acceptance. Previous research on risk perceptions concerning safety and health indicated that the higher the individuals' risk perceptions, the lower their acceptance of potable recycled water and non-potable recycled water (Dolnicar et al., 2011; Gibson \& Burton, 2014; Hurlimann \& Dolnicar, 2016; Kosovac et al., 2017; Ross et al., 2014). Previous research found that participants' emotions/risk perception can be influenced by environmental education (Fu \& Liu, 2017b) and messages or information from the authorities or media (Fielding \& Roiko, 2014; Goodwin et al., 2018a, 2018b; Hou et al., 2020; Price et al., 2010). Moreover, participants' emotions have been suggested in some researches to be a psychological factor. However, only a few experiments in this area have suggested why people feel specific emotions (Lease et al., 2014) and how these specific emotions can predict acceptance (Etale et al., 2020; Leong, 2016).

To explore how emotions predict public acceptance, this study suggested that recycled water was not the focus, but rather that some objects of care prompted individuals to care about recycled water when they felt that objects of care were being threatened. We hypothesized that these threatened objects trigger emotional responses to recycled water, and that emotional responses predict acceptance of recycled water. We then verified our hypothesis through two comparative studies in different samples. The methods used in the research were the quantitative comparison of acceptance and emotion intensity of the general population in different emotion profiles (study 1 ), and the qualitative comparison of objects of care and the emotions of water treatment experts with that of the general population (study 2). Study $1(N=378)$ measured how the types and intensity of emotions could affect public acceptance, which confirmed the hypothesis that positive emotions can promote public acceptance of recycled water while negative emotions will lower the levels of acceptance. Moreover, caring about recycled water tied individuals' perceptions of threat to their objects of care. In this premise, emotions of two groups (i.e., experts and general population), and how these emotions were affected by objects of care, were explored in study $2(N=357)$, which confirmed the hypothesis that individuals' specific emotions are related to their self-identities.

\section{Literature review}

\subsection{Objects of care and psychological distance}

When the verb "care" was defined in previous work, the meaning included people's interest in their objects of care; how a specific object could produce emotions of enjoyment or anger; and the act of protecting or guarding something (Wang et al., 2018). The major emphasis on caring about recycled water is not caring about recycled water itself, but a concern with the potential harm it brings or the influence it has on our valued objects (Kosovac et al., 2017). Research about pro-environmental action communicated a similar viewpoint (Brügger et al., 2015); it emphasized that the key to understanding people's responses to environment issues is to explore their perception of whether it threaten their valued objects or "objects of care". As connectors, the objects of care push recycled water and individuals closer together. Researchers in the ecological psychology branch have held that a "connector" is an object that links two or more individuals together. For example, construal level theory suggested that people can be understood by their whole physical, social, and psychological environment (Trope \& Liberman, 2010).

Psychological distance, which is the measurement of people's feelings about specific objects as close or distant, has become increasingly important in the environmental issue studies (Spence et al., 2011). According to the construal level theory, psychological distance can be defined in multiple dimensions including spatial distance, temporal distance, social distance, and hypothetical distance (Bar-Anan et al., 2006; Trope \& Liberman, 2010). The findings of previous studies showed that the impact of psychological factors on acceptance was mixed (Adapa, 2018; Dolnicar et al., 2011; Hurlimann et al., 2008).

The definition of psychological distance reasonably explained the relation between objects of care and individuals. According to previous study, emotions (including fear and hope) act as a behavioral guide via motivation to behavior (Zeelenberg et al., 2008). When objects of care are threatened by recycled water, an emotional response is triggered. For example, disgust, an aversive response to recycled water, is triggered when people feel that their health had been threatened by pathogen (Wester et al., 2015). Few works have explored emotions as a component of psychological distance (Boven et al., 2010). It has also been found that the closer the relationship was between the threatening objects and the individuals' objects of care, the stronger the emotions that were triggered (Fernando et al., 2014). Conversely, it has been found that stronger emotions shortened the distance between individuals' valued objects and threatening objects (Boven et al., 2010). Previous research has also indicated that increasing risk perception similarly shortened the psychological distance between individuals and recycled water (Brügger et al., 2015), which produced the same effect as a negative emotional response to recycled water, that was, to lower the acceptance of recycled water (Leong, 2016). To further explore psychological distance, the concepts of emotions and caring about recycled water are introduced next.

\subsection{Emotions and caring about recycled water}

Previous research on the public acceptance of recycled water found that emotions motivated acceptance of recycled water; however, which particular emotions drove the motivation were still unclear (Smith et al., 2018). Previous work on pro-environmental action indicated that negative emotions were related to pro-environmental behaviors 
(Smith \& Leiserowitz, 2014). However, it has been noted that the relationship between emotions and the acceptance of recycled water is not consistent in all contexts. Specifically, the aim of reducing negative emotions, as with that of enhancing positive emotions, is to promote acceptance by regulating different emotions. Previous studies indicated that negative emotions enhanced risk perceptions (Rozin et al., 2015), and that stronger risk perceptions lowered the acceptance (Ross et al., 2014). Similarly, positive emotions were found to motivate action by reducing risk perceptions (Lease et al., 2014). However, other research has shown that optimistic messages were less successful in increasing mitigation motivation (Hornsey \& Fielding, 2016). Recent research (Chapman et al., 2017) suggested that emotions could be used as a lever; pushing the correct side would produce the expected behavior. Risk perceptions for people of different self-identities also result in different emotional and behavioral responses under the same premise (Baggett et al., 2006; Böhm \& Pfister, 2015). This may explain why people have different responses to the same environmental issues (Siemer et al., 2007; Smith \& Kirby, 2009), although the results of this experiment were not obvious, the research ideas were used with the concept of objects of care in our study. Just like the previous experiment (Lefsrud \& Meyer, 2012), the responses of engineers from an oil company on environmental issues were investigated. The strongest emotion was generated by people who thought their identities and income were threatened by environmental problems. In this situation, the engineers' objects of care were identities and income. Further exploration on how objects of care associated with emotions is needed.

To explore why people care about recycled water and why they feel certain emotions about it, more types of samples are needed. Recent research on environmental policy emphasized that environmental scientists' emotional responses to environmental issues are very different from general people's emotion (Wang et al., 2018). There are reasons to believe that people who work on water treatment are more familiar with recycled water than others; thus, broader and stronger emotional responses to recycled water may be generated. The identity of a water treatment expert enables them to get closer to recycled water in a psychological distance.

\section{Study 1}

Recycled water in urban areas can be used for garden irrigation, road cleanup, swimming pool refills, car washes, laundry, toilet flushing, and drinking. Public acceptance of recycled water for these usages varies with changes in human contact.

To explore how public acceptance of recycled water could be affected by emotional responses, we did a quantitative analysis of emotional intensity in study 1 . To that end, study 1 entailed asking qualitative and quantitative questions about the emotional responses to recycled water and a measurement of the acceptance level of recycled water. This part emphasized how strongly the participants experienced the emotion. Previous study demonstrated that no single major emotion dominated participants' emotional responses; rather, it involved a combination of diverse emotions (Chapman et al., 2017). This meant that studying individual emotions separately was not useful in identifying the relationship between emotions and behaviors. Previous research suggested that anger, shame, and sympathy together constitute "strong pro-social emotion", and predict the collective action (Fernando et al., 2014).

The interplay of different emotions described a real emotional experience, which provided a link between emotions and behaviors. Using the emotion profile method, we conducted a clustering analysis to classify the participants into a number of groups, with each group having a similar pattern of emotional responses to recycled water. Different types of emotions were identified, such that each group represented an "emotion profile" to demonstrate specific people's emotional responses to recycled water. For example, one group might have had high levels of anger and low levels of happiness, and the other group was the reverse. To our knowledge, this was the first application of an emotion profile to research the public acceptance of recycled water.

For study 1, we collected data on emotions and acceptance via questionnaire. Different profiles of emotions were created, and then, the extent to which emotions affected public acceptance of recycled water was measured.

\subsection{Methods}

The study was conducted in cities in Shaanxi Province in northwest China, a region far from the sea with infrequent rainfall; thereby it is representative of most water-stressed areas in northern China. It means that the technology of desalination and rain water reusing is not applicable in these areas. In study 1 , in total 400 participants were recruited in exchange for RMB 15.00 to complete a series of online questionnaires. The valid sample $(N=378)$ contained 134 males and 244 females (the age ranges were from 18 to 65 and 65 and above).

Study 1 focused on the general population's emotional responses to recycled water only used for toilet flushing. Even though water used for toilet flushing might not have had direct contact with the human body, it is one of the critical matters to the daily life. For further research, recycled water acceptance comparisons between water treatment experts and general population were performed for toilet flushing and drinking in study 2. These two usages are life's necessities and represent two patterns of human contact and acceptance. Thus, the usage of toilet flushing, which represents low human contact usage, and drinking, which represents high human contact usage, were selected from a range of usages.

To investigate participants' emotional responses to recycled water for toilet flushing, quantitative questions about emotion intensity were asked. We sent questionnaires to the 378 participants who have been in pre-ex- 
periment via email for the next study, they were asked to rate on a 5-point scale how strongly they felt various emotions if they used recycled water to flush a toilet $(1=$ not at all, $5=$ very strongly). The emotion list was based on the previous research (Leviston et al., 2014), which include alarmed, angry, afraid, upset, sad, bored, depressed, miserable, content, relaxed, calm, excited, enthusiastic, and happy. The dependent variable was the acceptance of recycled water for toilet flushing; it was rated on a 5-point scale $(1=$ not at all, $5=$ very strongly accept $)$. Then the Kmeans clustering method was applied and computed using the squared Euclidean distance to group participants. Profiles of emotions were created by grouping the emotions with a similar intensity level. Then acceptances of participants from different profiles were compared.

Participants also asked about the things they care if they used recycled water for toilet flushing. Objects of care mentioned by the participants were extracted from the context of first association by RDQA, an easy to use tool to assist in the analysis of textual data. Subsequently we present a qualitative comparison of the high frequency associated words mentioned by people in different emotion profiles.

\subsection{Results}

The intensity of the various emotions for all participants is shown in Figure 1. The intensity is rated on a 5-point scale $(1=$ not at all, $5=$ very strongly).

The analysis of the K-means clustering showed that the four-cluster solution was acceptable and reliable. The findings showed the following four clusters: "Strong Positive Emotion" $(N=176)$, which included those who mostly experience positive emotions, especially content (4.27), calm (4.23), and relaxed (4.22), but with less negative emotions, such as bored (1.30) and angry (1.34); "Weak Positive Emotion" $(N=33)$, which included those who showed weaker positive emotions, such as content (1.97), excited (1.97), and happy (2.03), and who had relatively stronger negative emotions, especially alarmed (3.73), depressed (3.70), and upset (3.61); (We don't use "Strong Negative Emotion" because the intensity of negative emotion is not so strong as the intensity of positive emotion in "Strong Negative Emotion" group); "Ambivalent" $(N=92)$, which included those who experienced both positive and negative emotions strongly, such as content (3.61) and afraid (3.59); and "No Emotion" ( $N=77)$, which included those who were not usually sensitive to both emotions, such as miserable (1.26) and excited (1.59). The intensity of each of the emotions for the four clusters is shown in Figure 2.

To explore how the acceptance of recycled water could be differentiated by emotion profiles, we compared participants' acceptance in different clusters. Figure 3 illustrates the acceptance on a 5-point scale for each emotion profile.

The "Strong Positive Emotion" group was the most accepting of flushing a toilet with recycled water (4.523, with 5 representing very strongly accept). Moreover, the "Weak

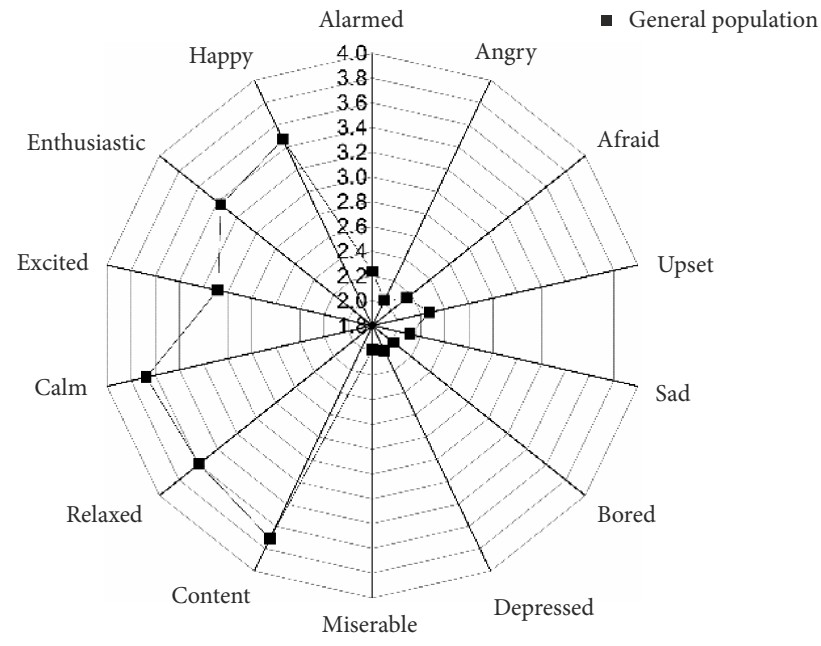

Figure 1. Average strength of 14 kinds of emotions for all participants (rated on a 5-point scale, with 5 representing very strongly)

Positive Emotion" group showed the lowest acceptance (3.182) of the four groups. The difference between these two groups was significant (i.e., $F=95.049, P=0.000<$ 0.001). The acceptance of the "Ambivalent" and "No Emotion" groups were 3.859 and 4.104, respectively. As the sample in the four clusters was unequal, a non-parametric multivariate test was performed to analyze the differences. The chi-square test showed that the difference between the "Strong Positive Emotion" and the "Weak Positive Emotion" group for the acceptance of recycled water was extremely significant (i.e., $\chi^{2}=75.377, P=0.000<0.001$ ). Similarly, difference of acceptance levels in the "Strong Positive Emotion" and "No Emotion" groups was also extremely significant (i.e., $\chi^{2}=20.293, P=0.000<0.001$ ). Moreover, the difference between the "Ambivalent" and the "Weak Positive Emotion" group was significant (i.e., $\left.\chi^{2}=17.970, P=0.001<0.05\right)$. Although the acceptance in "No Emotion" group is higher than that in "Ambivalent" group, the difference in acceptance between the "No Emotion" and "Ambivalent" group was not significant (i.e., $\chi^{2}=$ 8.841, $P=0.065>0.05$ ).

According to grouping, the participants' objects of care were analyzed and compared. The participants were asked: "how do you feel about flushing toilet with recycled water?" Not everyone mentioned objects of care, so the text emerged spontaneously. We focused on their first association. Participants mentioned 79 kinds of objects of care, from the most frequent words (e.g., health, environment, and water resources) to specific objects (e.g., bacteria, chronic injuries). The "Strong Positive Emotion" group mentioned the broadest range of objects (72). The "Weak Positive Emotion" group mentioned 22 objects, although there were only 33 people in this group. The "Ambivalent" and "No Emotion" groups mentioned 51 and 41 kinds of objects, respectively. Figure 4 shows objects of care mentioned by each cluster group in terms of frequency due to the different sample sizes. 


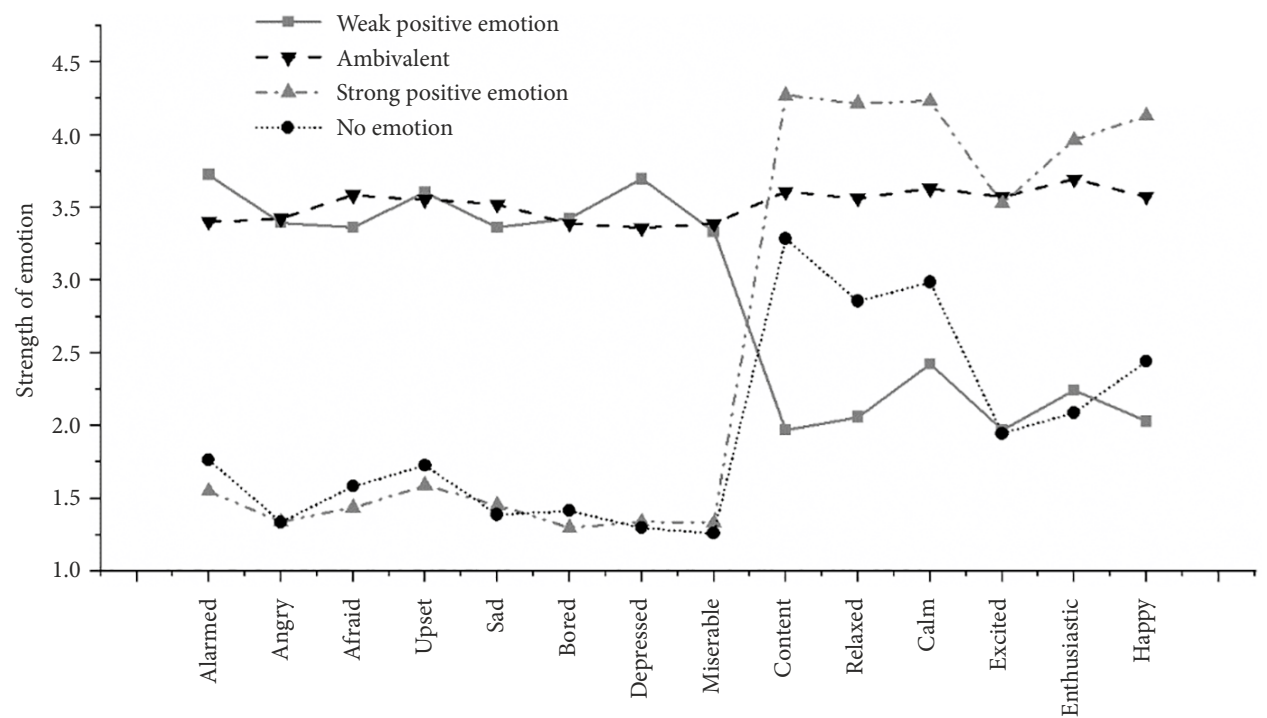

Figure 2. The intensity of emotions to recycled water for each profile: Weak Positive Emotion, Ambivalent, Strong Positive Emotion, and No Emotion

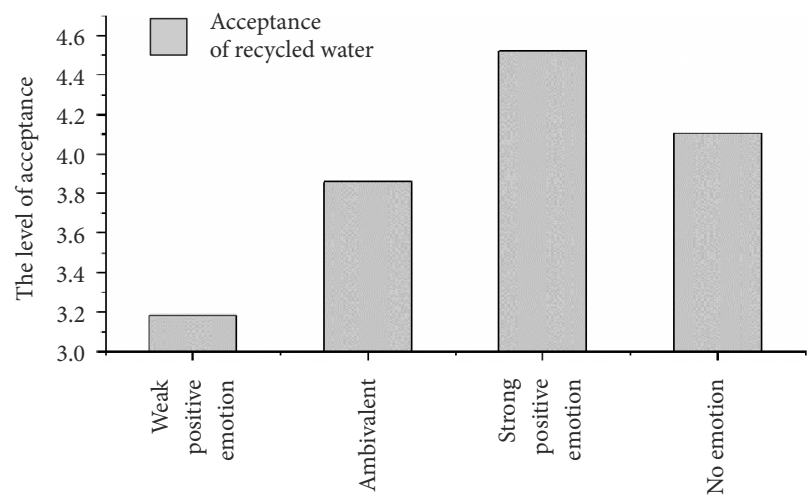

Figure 3. Acceptance of recycled water for each emotion profile: Weak Positive Emotion, Ambivalent, Strong Positive Emotion, and No Emotion

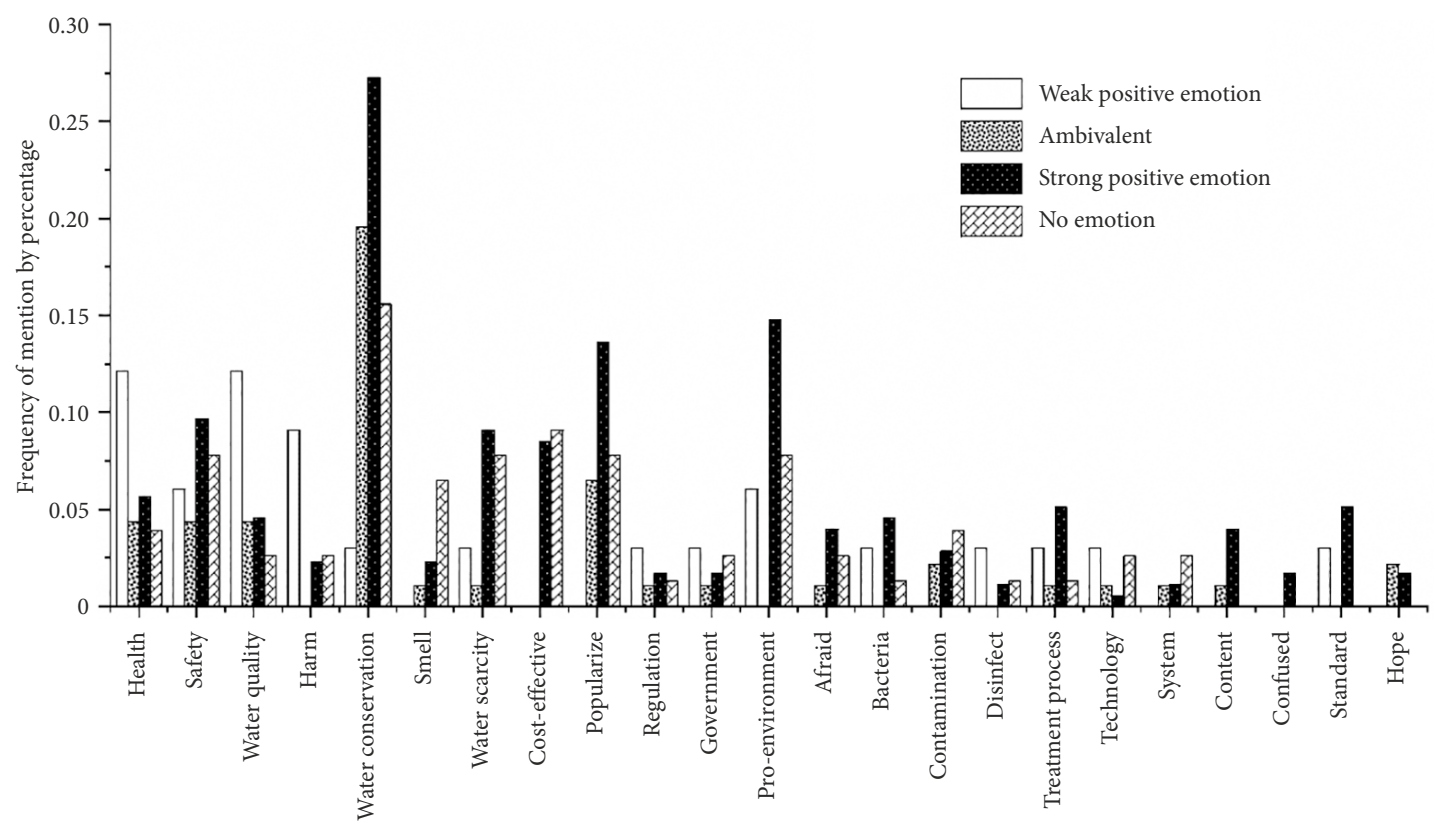

Figure 4. The frequency of "objects of care" mentioned by each emotion profile, showing objects mentioned frequently by four groups 
Table 1 . Top 5 most frequently mentioned objects among the four groups

\begin{tabular}{|c|l|l|l|l|}
\hline Rankings & \multicolumn{1}{|c|}{ Weak Positive Emotion } & \multicolumn{1}{|c|}{ Ambivalent } & Strong Positive Emotion & \multicolumn{1}{c|}{ No Emotion } \\
\hline 1 & health & water conservation & water conservation & water conservation \\
\hline 2 & water quality & popularize & pro-environment & cost-effective \\
\hline 3 & harm & health & popularize & popularize \\
\hline 4 & safety & safety & safety & water scarcity \\
\hline 5 & pro-environment & water quality & water scarcity & safety \\
\hline
\end{tabular}

The objects that were the most commonly mentioned by the four clusters included water conservation, popularity, and safety, as can be seen in Table 1 .

\subsection{Discussion}

In this study, the quantitative results showed that the emotion profiles presented evident diversity in levels of acceptance. The "Strong Positive Emotion" group (highly content, calm, and relaxed) was more accepting of recycled water than the other three groups. The "No Emotion" group showed fewer acceptances than the "Strong Positive Emotion" group, but more acceptance than the "Ambivalent" group. Moreover, the "Weak Positive Emotion" group (not very content or excited, but highly alarmed and depressed) showed the lowest acceptance. To sum up, this study demonstrated that positive emotional responses to recycled water predict acceptance of recycled water while negative emotional reaction predict less acceptance or more resistance of recycled water. The findings were consistent with a number of previous studies (Gibson \& Burton, 2014; Morgan \& Grant-Smith, 2014; Nancarrow et al., 2008, 2009). Although the intensities of both negative and positive emotions in the "No Emotion" group were lower than those in the "Ambivalent" group, the "No Emotion" group showed higher acceptance than the "Ambivalent" group. It shows that people with broader and stronger emotion have lower acceptance. We will further explore this issue in study 2 .

Emotional responses also depended on the perceptions of a threat to the valued objects of the individual (Brügger, 2013). More precisely, objects of care varied from person to person, but the emotional responses generated from threat perceptions were similar and predictable, and these emotions have strong influence on behaviors (Fielding et al., 2018). However, it should be noted that emotional response was not the reason for the behavior, but a symptom. More specifically, objects of care that linked individuals to recycled water were beneficial in understanding the interaction between emotions and behaviors. In our study, recycled water was not deemed an "object of care", because people don't need to protect or enjoy it. Instead, recycled water was deemed a threat to the objects that people do care about.

Next, a qualitative comparison of objects of care showed that people in different emotion profiles cared about different objects. The word mentioned with the highest frequency by participants who had stronger posi- tive emotions (those in the "Strong Positive Emotions", "Ambivalent", and "No Emotion" groups) was "water conservation". However, participants with stronger negative emotions (those in the "Weak Positive Emotions" and "Ambivalent" group) mentioned the word "health" the most frequently. This demonstrated that people who care more about water conservation tend to generate positive emotional responses to recycled water, whereas people who care more about health have more negative emotional responses to recycled water. This may be because more objects of care means higher levels of concern, which shortened the psychological distance between individuals and recycled water (Spence et al., 2011). For people who care more about health - a more personally relevant word, the increasing risk perception was associated with the decreasing psychological distance between individuals and recycled water, which resulted in the lower level of acceptance (Ross et al., 2014). That may also have been why the level of acceptance of participants in the "Weak Positive Emotions" group was lower than that of the other three groups.

Participants in the "Strong Positive Emotions" group mentioned "water conservation", "pro-environment," and "popularize" more often. In contrast, people in the "Weak Positive Emotions" group mentioned "safety", "health", "bacteria", and "contamination" more often. This showed the unique objects of care of these two groups. People who cared about water conservation and environment had stronger positive emotions, and these positive emotions may have motivated them to accept recycled water. However, people who cared more about safety and health had fewer positive emotions and more negative emotions, and these more personally relevant things increase perceptions of personal risk, then the negative emotions may have led them to resist recycled water. However, in the "Ambivalent" group, participants experienced negative emotions as strongly as people in the "Weak Positive Emotions" group, and stronger positive emotions made the former group more accepting of recycled water than the latter.

In study 1 , we aimed to research the emotional responses of the general population to recycled water used for toilet flushing, and the association between these emotions and individuals' acceptance of recycled water. The emotions were summarized and classified into several emotion profiles, which helped us to understand how emotions affected acceptance. As a connector between emotions and acceptance, objects of care in different profiles were also compared. 


\section{Study 2}

In study 2, we further researched the relation between objects of care and acceptance in two sample groups - the general population and water treatment experts, and examined whether the objects of care and acceptance level of the water treatment experts were similar to that of the general population in study 1 . Study 2 explored the water treatment experts' and general population's acceptance to the use of recycled water for toilet flushing and drinking. We aimed to gauge participants' acceptance level and what they cared about.

\subsection{Methods}

Totally 357 valid questionnaires were collected through the internet in study 2. Questionnaires were sent to the water treatment experts $(N=34,9$ females and 25 males, mean age 46 , who have a deep understanding of water treatment technology) via emails. The data of the general population were collected via an online questionnaire, in total 323 participants were recruited in exchange for RMB 10.00 (where there were 204 females and 119 males, and the ages ranged from 18 to 65 and 65 above). Participants' acceptance (rated on a 100-point scale, where $0=$ not at all, and $100=$ very strongly accept) of recycled water for the two usages and their reasons were asked about. Then the data were analyzed with non-parametric test between samples with large different sizes (34 versus 323 ).

Participants were also asked "what do you care about if the recycled water used for toilet flushing/drinking?" We focused on the content of the first association, which comes from free associations and would be the most intuitive response to the recycled water. Then we used RQDA package to analyze the text from the experts and the general population. First, the highest frequency words and phrases were extracted from the text of participants' questionnaires, as their objects of care. Second, a quantitative comparison of individuals' acceptance to recycled water between the expert and general population was conducted. Finally, a qualitative comparison of the objects of care was made between the experts and the general population in terms of range and frequency.

\subsection{Results}

A Mann-Whitney $\mathrm{U}$ test was run to determine if there were differences in acceptance levels for the usage of toilet flushing and drinking between the experts and the general population. For the usage of toilet flushing, acceptance levels for the experts (mean rank $=178.26$ ) and the general population (mean rank $=179.08$ ) were not statistically significantly different, $U=5466, z=-0.049, p=$ 0.961; For the usage of drinking, acceptance levels for the experts (mean rank $=136.71$ ) and the general population (mean rank $=183.45)$ were not statistically significantly different, $U=4053, z=-2.553, p=0.011$. The mean rank for the general population was always higher than that for the experts in both types of usage.

The most frequent words mentioned by participants for toilet flushing can be seen in Table 2. For both the experts and the general population, the most frequent code was "water conservation", which pointed out the advantage of this usage of recycled water. Experts mentioned "water resources", "quality criteria", and "public program" frequently, which indicated what they cared about. For the general population, the second most frequent code was "pro-environment", which emphasized the merits of recycled water, followed by "clean" and "water resources", which showed what they care about.

As Table 3 shows, the most frequently mentioned codes for the two samples for the use of drinking were totally different from that for the use of toilet flushing. For both the experts and the general population, the most frequent code was "health", which showed what they care about most. Other frequently used codes for the experts were "safety" and "clean", and the general population mentioned "clean" and "quality criteria," which summarized their main concerns about potable recycled water.

According to the two tables above, though the numbers of the codes were different, the frequency was similar for the two samples, as the sample size was different.

Table 2. The highest-frequency codes for two samples for the use of toilet flushing

\begin{tabular}{|c|l|c|l|c|}
\hline Rankings & \multicolumn{1}{|c|}{ Experts $(N=34)$} & Number & General population $(N=323)$ & Number \\
\hline 1 & Water conservation & 8 & Water conservation & 104 \\
\hline 2 & Water resources & 7 & Pro-environment & 66 \\
\hline 3 & Quality criteria & 5 & Clean & 37 \\
\hline 4 & Public program & 4 & Water resources & 28 \\
\hline 5 & Pipe & 4 & Cost efficient & 27 \\
\hline 6 & Citizens & 4 & Water quality & 24 \\
\hline 7 & Cost & 4 & Waste water & 23 \\
\hline 8 & Tap water & 3 & Reutilization & 18 \\
\hline 9 & Water quality & 3 & Community & 13 \\
\hline 10 & Health & 3 & Safety & 12 \\
\hline
\end{tabular}


Table 3. The codes with the highest frequency for the two samples for the use of drinking

\begin{tabular}{|c|l|c|l|c|}
\hline Rankings & \multicolumn{1}{|c|}{ Experts $(N=34)$} & Number & General population $(N=323)$ & Number \\
\hline 1 & Health & 9 & Health & 112 \\
\hline 2 & Safety & 6 & Clean & 63 \\
\hline 3 & Clean & 6 & Quality criteria & 49 \\
\hline 4 & Waste water & 6 & Safety & 39 \\
\hline 5 & Quality criteria & 4 & Water quality & 34 \\
\hline 6 & Water quality & 3 & Psychological & 26 \\
\hline 7 & Psychological & 3 & Water resources & 25 \\
\hline 8 & ease & 3 & Water conservation & 18 \\
\hline 9 & Pollution & 2 & Disinfect & 15 \\
\hline 10 & Government & & 15 \\
\hline
\end{tabular}

However, there was a great difference in the scope of the codes between the two samples. For toilet flushing, many experts mentioned "pipe" and "tap water", but no one in the general population mentioned these words. For drinking, a number of experts mentioned "ease", "content", and "disgust", which showed the positive and negative emotional responses to recycled water directly. However, many individuals in the general people mentioned the word "harm", which meant that they were afraid of the harm brought by potable recycled water, but they mentioned few emotion-related words directly in their text. Moreover, the two types of samples expressed a different range of objects of care, which might have led people to accept or resist recycled water.

\subsection{Discussion}

Study 2 explored the participants' acceptance to recycled water and objects of care for different usages in two specific groups: water treatment experts and general population. The mean rank suggested that general population seem to accept recycled water more than experts for toilet flushing and drinking, the difference being more obvious for drinking. The findings of free associations showed a significant difference in emotional responses. When comparing the frequency of words of the experts with that of the general population, we found that content and alarmed were found to be the emotions most frequently expressed in the expert group, whereas fewer emotions were expressed by the general population. These two response patterns were similar to the patterns of "Ambivalent" group and "No Emotion" group in study 1 . The emotional response pattern in the expert group corresponded to that in the "Ambivalent" group. More specifically, experts and participants in "Ambivalent" group presented relatively strong positive and negative emotions. Meanwhile, the general population group and "No Emotion" group expressed weak responses to both positive and negative emotions. Previous study confirmed that negative emotion would reduce the level of acceptance by increasing individuals' risk perceptions as the intermediary (Nancarrow et al., 2008, 2009). In this study, participants who had less emotion are more inclined to accept recycle water than those who had more ambivalent emotions. The findings are similar to those in a previous study (Greenaway \& Fielding, 2020) that found that people who held ambivalent attitude are more susceptible to negative emotions, thereby increasing their risk perceptions and then reducing the acceptance.

Among the general population, individuals paid more attention to cognition than emotion. Their discussions included, for example, "whether using recycled water is beneficial to environment and water resources," "to what extent they will be affected by recycled water for different usages", and "what they think if a recycled water project is upcoming". In fact, compared with the discussions of the experts, the discussions of the general population were more relevant to the characteristics of recycled water. This is because the general population cared more about recycled water use as an issue, and paid more attention to the treatment process, technology, and water quality criteria. However, the general population rarely linked recycled water to other fields of their daily life. Thus, the general population expressed less emotion.

On the other hand, the experts proposed that more objects were affected by recycled water, such as potable water pipes, soil, and water pollution. As displayed by the text, the experts worried that the extra provision of recycled water could affect the existing pipeline for tap water. For experts, recycled water might have affected more areas of their life. This is to say that the individuals cared more about the objects affected by the recycled water than the recycled water itself. The experts' emotional responses represented in the text showed that what they cared about was closely associated with recycled water. The entities that they felt were affected by recycled water included health and water resources. In other words, caring about health and water resources gave rise to caring about recycled water, and vice versa. Experts were more sensitive to recycled water because caring about more objects (such as health and water resources) pushed them closer to recycled water. Furthermore, using recycled water involved multiple self-identities for experts that more broadly related to other fields and more diverse emotions. 
Objects of care that were affected by recycled water prompted experts to experience multiple self-identities, which included personal identity, professional identity, and user identity. These diverse identities even caused conflicting emotions. For instance, experts felt content and calm as professionals, but they felt alarmed and upset as users. On the other hand, less of the general population member's life was affected by recycled water, so the population felt less closely affected by recycled water, and the intensity and scope of their emotions was weaker than that of the experts. Therefore, few emotion-related words were mentioned by the general population.

\section{General discussion}

\subsection{Overview of findings}

The emotions were associated with the threatened objects of care. The strength of the emotions corresponded to the closeness between the individual and the threatened objects (such as health, water quality, and water resources). By testing the sample, the diversity in the participants' acceptance was explained through profiles of emotions. Participants with different levels of acceptance experienced various range and intensity emotions and presented very differently objects of care in study 1 . In study 2 , it was noticeable that the experts presented more objects of care, and broader and stronger emotions, and that they were more obviously resistant to recycled water for drinking than the general population. The finding confirmed our conceptualization of "caring about recycled water" that was mentioned in the introduction. Objects of care linked individuals to recycled water use, and that is why some people had more emotions than others toward the use of recycled water.

People resisted recycled water when they perceived that their objects of care were under threat. Differentiating the core objects of care contributed to our understanding of the acceptance of recycled water. By analyzing the emotional responses and psychological distance of individuals to recycled water, we demonstrated that the threat perception of objects of care might have changed the psychological distance between individuals and recycled water. We found that the experts participated in recycled water use in more ways than the general population did, and that their degree of concern varied with self-identities even to the same objects. Knowing whether more knowledge about recycled water can lower the level of acceptance has great enlightenment on governmental publicity strategy of recycled water. How to let people know more about recycle water without triggering strong negative emotion is crucial.

\subsection{Limitations and future directions}

First, an online questionnai're was used in this research so that participants would not know each other. The increased social distance broadened the psychological dis- tance between the general population and recycled water, and consequently affected the acceptance. For instance, individuals were more accepting of recycled water used for garden irrigation than that for laundry. This was because the far spatial distance between individuals and garden irrigation use broadened the psychological distance between them, thereby lowering their resistance to recycled water. A comparison of the impact of social, temporal, and spatial distance on emotional responses can be carried out in the future. Future studies can also try to explore how emotions would be affected by familiar relationship among individuals in a community, and how emotions would be affected by the launch time of a recycled water project.

Second, although respondents were divided into two groups, water treatment experts and the general population, these groups can be further divided into more subgroups. The great diversity of emotions (including contentedness, ease, and disgust) in the experts suggested that this group subdivision is needed. The sample of experts in our study $(N=34)$ was too small to be subdivided, so more samples are required in future research. Members of the general population can also be subdivided into groups, such as environmentalists and activists.

Last but not least, data on emotions and acceptance were collected via a questionnaire, so that meant that the strength of the emotions could be judged by the participants themselves. But it also meant the strength might not have been quantified accurately. In the future, an electroencephalograph (EEG) can be used to explore individuals' real emotional responses to recycled water and to find out why the brain induces those emotions.

\section{Conclusions}

We defined what it means to care about recycled water and explored why people have specific emotions and how to connect these emotions to their acceptance of recycled water. We also investigated objects of care, emotions, and the acceptance by experts and the general population.

The research described the relationship among objects of care, emotional responses, and the acceptance of recycled water. The determination of objects of care was made based on valued objects, people, places, and self-identities. Our findings suggest that objects of care that shorten the distance between people and recycled water may be critical to understanding why some people feel more strongly about recycled water than others, and how emotions can predict their acceptance. To improve the acceptance of recycled water, what people care about and their distinct self-identities can be used to motivate their behaviors. Connecting caring about recycled water with diverse objects of care can contribute to improving the relationship between individuals and recycled water. The discussions we observed suggested that using recycled water is not a separate matter, but is related to many fields in life, and may even include the environment in which we live. 


\section{Acknowledgements}

This work was supported by the National Natural Science Foundation of China (No. 71874135) and MOE (Ministry of Education of China) Project of Humanities and social Sciences (No. 18YJA630068). The authors would like to thank the participants who volunteered in this study.

\section{References}

Adapa, S. (2018). Factors influencing consumption and anti-consumption of recycled water: Evidence from Australia. Journal of Cleaner Production, 201, 624-635.

https://doi.org/10.1016/j.jclepro.2018.08.083

Baggett, S., Jeffrey, P., \& Jefferson, B. (2006). Risk perception in participatory planning for water reuse. Desalination, 187(1/3), 149-158. https://doi.org/10.1016/j.desal.2005.04.075

Bar-Anan, Y., Liberman, N., \& Trope, Y. (2006). The association between psychological distance and construal level: Evidence from an implicit association test. Journal of Experimental Psychology: General, 135(4), 609.

https://doi.org/10.1037/0096-3445.135.4.609

Böhm, G., \& Pfister, H.-R. (2015). The perceiver's social role and a risk's causal structure as determinants of environmental risk evaluation. Journal of Risk Research, 20, 1-28.

https://doi.org/10.1080/13669877.2015.1118148

Boven, L.V., Kane, J., Mcgraw, A. P., \& Dale, J. (2010). Feeling close: Emotional intensity reduces perceived psychological sistance. Journal of Personality and Social Psychology, 98(6), 872-885. https://doi.org/10.1037/a0019262

Browning, A., Ormerod, K., \& A. Scott, C. (2011). Testing the climate for non-potable water reuse: Opportunities and challenges in water-scarce urban growth corridors. Journal of Environmental Policy \& Planning, 13, 253-275. https://doi.org/10.1080/1523908X.2011.594597

Brügger, A. (2013). Fear appeals and localising climate change: neither is a panacea to motivate action on climate change. A social psychological perspective [ $\mathrm{PhD}$ thesis]. University of Exeter.

Brügger, A., Dessai, S., Devinewright, P., Morton, T. A., \& Pidgeon, N. F. (2015). Psychological responses to the proximity of climate change. Nature Climate Change, 5(12), 1031-1037. https://doi.org/10.1038/nclimate2760

Chapman, D. A., Lickel, B., \& Markowitz, E. M. (2017). Reassessing emotion in climate change communication. Nature Climate Change, 7(12), 850-852. https://doi.org/10.1038/s41558-017-0021-9

Chen, W., Bai, Y., Zhang, W., Lyu, S., Jiao, W., \& Vincenzo, T. (2015). Perceptions of different stakeholders on reclaimed water reuse: The case of Beijing, China. Sustainability, 7(7), 9696-9710. https://doi.org/10.3390/su7079696

Chen, Z., Wu, Q., Wu, G., \& Hu, H.-Y. (2017). Centralized water reuse system with multiple applications in urban areas: Lessons from China's experience. Resources Conservation and Recycling, 117, 125-136. https://doi.org/10.1016/j.resconrec.2016.11.008

Dolnicar, S., \& Schafer, A. I. (2009). Desalinated versus recycled water: public perceptions and profiles of the accepters. Journal of Environmental Management, 90(2), 888-900.

https://doi.org/10.1016/j.jenvman.2008.02.003

Dolnicar, S., Hurlimann, A., \& Gruen, B. (2011). What affects public acceptance of recycled and desalinated water? Water Research, 45(2), 933-943.

https://doi.org/10.1016/j.watres.2010.09.030
Etale, A., Fielding, K., Schäfer, A. I., \& Siegrist, M. (2020). Recycled and desalinated water: Consumers' associations, and the influence of affect and disgust on willingness to use. Journal of Environmental Management, 261, 110217.

https://doi.org/10.1016/j.jenvman.2020.110217

Fernando, J. W., Kashima, Y., \& Laham, S. M. (2014). Multiple emotions: a person-centered approach to the relationship between intergroup emotion and action orientation. Emotion, 14(4), 722-732. https://doi.org/10.1037/a0036103

Fielding, K. S., \& Roiko, A. H. (2014). Providing information promotes greater public support for potable recycled water. Water Research, 61, 86-96.

https://doi.org/10.1016/j.watres.2014.05.002

Fielding, K. S., Dolnicar, S., \& Schultz, T. (2018). Public acceptance of recycled water. International Journal of Water Resources Development, 35(1), 1-36.

https://doi.org/10.1080/07900627.2017.1419125

Fu, H., \& Liu, X. (2017a). Research on the phenomenon of Chinese residents' spiritual contagion for the reuse of recycled water based on SC-IAT. Water, 9(11), 846.

https://doi.org/10.3390/w9110846

Fu, H., \& Liu, X. (2017b). A study on the impact of environmental education on individuals' behaviors concerning recycled water reuse. Eurasia Journal of Mathematics Science and Technology Education, 13(10), 6715-6724. https://doi.org/10.12973/ejmste/78192

Fu, H., Manogaran, G., Wu, K., Cao, M., Jiang, S., \& Yang, A. (2020). Intelligent decision-making of online shopping behavior based on internet of things. International Journal of Information Management, 50, 515-525.

https://doi.org/10.1016/j.ijinfomgt.2019.03.010

Garcia-Cuerva, L., Berglund, E. Z., \& Binder, A. R. (2016). Public perceptions of water shortages, conservation behaviors, and support for water reuse in the US. Resources Conservation and Recycling, 113, 106-115.

https://doi.org/10.1016/j.resconrec.2016.06.006

Gibson, F. L., \& Burton, M. (2014). Salt or sludge? Exploring preferences for potable water sources. Environmental and Resource Economics, 57(3), 453-476.

https://doi.org/10.1007/s10640-013-9672-9

Goodwin, D., Raffin, M., Jeffrey, P., \& Smith, H. M. (2018a). Evaluating media framing and public reactions in the context of a water reuse proposal. International Journal of Water Resources Development, 34(6), 848-868. https://doi.org/10.1080/07900627.2017.1347085

Goodwin, D., Raffin, M., Jeffrey, P., \& Smith, H. M. (2018b). Informing public attitudes to non-potable water reuse - The impact of message framing. Water Research, 145, 125-135. https://doi.org/10.1016/j.watres.2018.08.006

Greenaway, T., \& Fielding, K. S. (2020). Positive affective framing of information reduces risk perceptions and increases acceptance of recycled water. Environmental Communication, 14(3), 391-402. https://doi.org/10.1080/17524032.2019.1680408

Gu, Q., Chen, Y., Pody, R., Cheng, R., Zheng, X., \& Zhang, Z. (2015). Public perception and acceptability toward reclaimed water in Tianjin. Resources Conservation and Recycling, 104, 291-299. https://doi.org/10.1016/j.resconrec.2015.07.013

Hou, C., Fu, H., Liu, X., \& Wen, Y. (2020). The effect of recycled water information disclosure on public acceptance of recycled water - Evidence from residents of Xi'an, China. Sustainable Cities and Society, 61, 102351.

https://doi.org/10.1016/j.scs.2020.102351

Hou, C., Wen, Y., Liu, X., \& Dong, M. (2021). Impacts of regional water shortage information disclosure on public acceptance 
of recycled water - evidences from China's urban residents. Journal of Cleaner Production, 278, 123965.

https://doi.org/10.1016/j.jclepro.2020.123965

Hurlimann, A., \& Dolnicar, S. (2010). When public opposition defeats alternative water projects - the case of Toowoomba Australia. Water Research, 44(1), 287-297.

https://doi.org/10.1016/j.watres.2009.09.020

Hurlimann, A., \& Dolnicar, S. (2016). Public acceptance and perceptions of alternative water sources: a comparative study in nine locations. International Journal of Water Resources Development, 32(4), 650-673.

https://doi.org/10.1080/07900627.2016.1143350

Hurlimann, A., Hemphill, E., McKay, J., \& Geursen, G. (2008). Establishing components of community satisfaction with recycled water use through a structural equation model. Journal of Environmental Management, 88(4), 1221-1232.

https://doi.org/10.1016/j.jenvman.2007.06.002

Hurlimann, A., \& McKay, J. (2004). Attitudes to reclaimed water for domestic use: Part 2. Trust. Water, 31, 40-45.

Hornsey, M. J., \& Fielding, K. S. (2016). A cautionary note about messages of hope: Focusing on progress in reducing carbon emissions weakens mitigation motivation. Global Environmental Change, 39, 26-34.

https://doi.org/10.1016/j.gloenvcha.2016.04.003

Kosovac, A., Hurlimann, A., \& Davidson, B. (2017). Water experts' perception of risk for new and unfamiliar water projects. Water, 9(12), 976. https://doi.org/10.3390/w9120976

Lease, H. J., MacDonald, D. H., \& Cox, D. N. (2014). Consumers' acceptance of recycled water in meat products: The influence of tasting, attitudes and values on hedonic and emotional reactions. Food Quality and Preference, 37, 35-44. https://doi.org/10.1016/j.foodqual.2014.04.002

Lee, H., \& Tan, T. P. (2016). Singapore's experience with reclaimed water: NEWater. International Journal of Water Resources Development, 32(4), 611-621.

https://doi.org/10.1080/07900627.2015.1120188

Lefsrud, L. M., \& Meyer, R. E. (2012) Science or science fiction? Professionals' discursive construction of climate change. Organization Studies, 33(11), 1477-1506.

https://doi.org/10.1177/0170840612463317

Leong, C. (2016). The role of emotions in drinking recycled water. Water, 8(11), 548. https://doi.org/10.3390/w8110548

Leviston, Z., Price, J., \& Bishop, B. (2014). Imagining climate change: The role of implicit associations and affective psychological distancing in climate change responses. European Journal of Social Psychology, 44(5), 441-454.

https://doi.org/10.1002/ejsp.2050

Morgan, E., \& Grant-Smith, D. (2014). Tales of science and defiance: the case for co-learning and collaboration in bridging the science/emotion divide in water recycling debates. Journal of Environmental Planning and Management, 58(10), 17701788. https://doi.org/10.1080/09640568.2014.954691

Nancarrow, B. E., Leviston, Z., Po, M., Porter, N. B., \& Tucker, D. I. (2008). What drives communities' decisions and behaviours in the reuse of wastewater. Water Science \& Technology, 57(4), 485-491. https://doi.org/10.2166/wst.2008.160

Nancarrow, B. E., Leviston, Z., \& Tucker, D. I. (2009). Measuring the predictors of communities' behavioural decisions for potable reuse of wastewater. Water Science \& Technology, 60(12), 3199-3209. https://doi.org/10.2166/wst.2009.759
Price, J., Fielding, K. S., Gardner, J., Leviston, Z., \& Green, M. (2010). Developing effective messages about potable recycled water: The importance of message structure and content. Water Resources Research, 51, 2174-2187.

https://doi.org/10.1002/2014WR016514

Ross, V. L., Fielding, K. S., \& Louis, W. R. (2014). Social trust, risk perceptions and public acceptance of recycled water: Testing a social-psychological model. Journal of Environmental Management, 137, 61-68.

https://doi.org/10.1016/j.jenvman.2014.01.039

Rozin, P., Haddad, B., Nemeroff, C., \& Slovic, P. (2015). Psychological aspects of the rejection of recycled water: Contamination, purification and disgust. Judgment and Decision Making, 10(1), 50-63.

Savchenko, O. M., Kecinski, M., Li, T., Messer, K. D., \& Xu, H. (2018). Fresh foods irrigated with recycled water: A framed field experiment on consumer responses. Food Policy, 80, 103-112. https://doi.org/10.1016/j.foodpol.2018.09.005

Siemer, M., Mauss, I., \& Gross, J. J. (2007). Same situation - different emotions: How appraisals shape our emotions. Emotion, 7(3), 592-600. https://doi.org/10.1037/1528-3542.7.3.592

Smith, C. A., \& Kirby, L. D. (2009). Putting appraisal in context: Toward a relational model of appraisal and emotion. Cognition and Emotion, 23, 1352-1372. https://doi.org/10.1080/02699930902860386

Smith, N., \& Leiserowitz, A. (2014). The role of emotion in global warming policy support and opposition. Risk Analysis, 34(5), 937-948. https://doi.org/10.1111/risa.12140

Smith, H. M., Brouwer, S., Jeffrey, P., \& Frijns, J. (2018). Public responses to water reuse - Understanding the evidence. Journal of Environmental Management, 207, 43-50. https://doi.org/10.1016/j.jenvman.2017.11.021

Spence, A., Poortinga, W., \& Pidgeon, N. (2011). The psychological distance of climate change. Risk Analysis, 32, 957-972. https://doi.org/10.1111/j.1539-6924.2011.01695.x

Trope, Y., \& Liberman, N. (2010). Construal-level theory of psychological distance. Psychological Review, 117(2), 440-463. https://doi.org/10.1037/a0018963

UNESCO. (2015). The United Nations world water development report 2015: Water for a sustainable world [United Nations World Water Assessment Programme (WWAP)]. United Nations Educational, Scientific and Cultural Organization, Paris.

Wang, S., Leviston, Z., Hurlstone, M., Lawrence, C., \& Walker, L. (2018). Emotions predict policy support: Why it matters how people feel about climate change. Global Environmental Change-Human and Policy Dimensions, 50, 25-40. https://doi.org/10.1016/j.gloenvcha.2018.03.002

Wester, J., Timpano, K. R., Cek, D., \& Broad, K. (2016). The psychology of recycled water: Factors predicting disgust and willingness to use. Water Resources Research, 52(4), 3212-3226. https://doi.org/10.1002/2015WR018340

Wester, J., Timpano, K. R., Çek, D., Lieberman, D., Fieldstone, S. C., \& Broad, K. (2015). Psychological and social factors associated with wastewater reuse emotional discomfort. Journal of Environmental Psychology, 42, 16-23. https://doi.org/10.1016/j.jenvp.2015.01.003

Zeelenberg, M., Nelissen, R., Breugelmans, S., \& Rik, P. (2008). On emotion specificity in decision making. Judgment and Decision Making, 3(1), 18-27. 